\title{
EFFECTS OF NANO-CLAY ON BIOLOGICAL RESISTANCE OF WOOD- PLASTIC COMPOSITE AGAINST FIVE WOOD-DETERIORATING FUNGI
}

\author{
E. Bari', H. R. Taghiyari, ${ }^{2, \wedge}$ O. Schmidt ${ }^{3}$ A. Ghorbani ${ }^{4}$, H. Aghababaei
}

\begin{abstract}
Effects of nano-clay on weight loss of wood-plastic composites (WPC) by five fungi were studied. Nanoclay particles of 20 to $50 \mathrm{~nm}$ size were applied at 2, 4, and $6 \%$ WPC of $0,90 \mathrm{~g} / \mathrm{cm}^{3}$ density. The white-rot fungi Physisporinus vitreus, Pleurotus ostreatus and Trametes versicolor as well as the brown-rot species Antrodia vaillantii and Coniophora puteana were used. Mass loss tests were conducted according to the European standard. The highest (3.2\%) and lowest $(0,2 \%)$ mass losses were produced by $T$. versicolor and $P$. vitreus in the control and 6\%-nanoclay treatments, respectively. Obviously the weight loss of WPC depends on the fungus species. Although weight losses were extremely low, nano-clay considerably inhibited the growth of wood-deteriorating fungi. Mass loss correlated with water absorption.
\end{abstract}

Keywords: Fungal degradation, nano-clay, Populus nigra, water absorption, wood-plastic composite.

\section{INTRODUCTION}

When WPCs first entered the market, they were thought to be impervious to biological attack. Wood particles were presumed to be completely encapsulated by the plastic, thereby protecting them from both moisture and fungal attack (Morrell et al. 2006). However, observations of early WPC used as decks in Florida showed fungal fruiting bodies on the surface. Subsequent studies clearly proved that the wood particles in many WPCs remained susceptible to fungal degradation (Laks et al. 2000, Mankowski and Morrell 2000, Pendleton et al. 2002).

Great improvements have been made ever since in WPC or preservative formulations to increase durability against different biotic and abiotic agents (Palanti et al. 2012). Nanotechnology has been utilized in different sciences such as molecular electronics (Pati 2012), materials extraction (Moghimi 2012), spectroscopic and microscopic analyses of DNA (Saber et al. 2013). In wood science and technology, metal nanoparticles increased heat transfer from the surface to the inner part of wood to be used in heat-treatment of solid woods and wood-composite materials (Taghiyari and Farajpour 2013). They also exhibited antibacterial and antifungal properties. Mineral nanofibers increased heat-conductivity coefficient to reduce heat-gradient and hot-press time in composite-board manufacturing, as well as increased the fire-retarding properties. Nanoclay improved dimensional stability in WPC (DePolo and Baird 2009). The influence of wood species on physical and mechanical properties of WPC was studied in details (Stark 1997, Gacitua 2008). The effects of wood particles on water sorption, biodegradation, metal corrosion and color change after exterior exposure were reported (Kim et al. 2008). The susceptibility of some wood species against two fungal species was studied (Fabiyi et al. 2011). The present study extends on five fungi.

\footnotetext{
Department of Wood and Paper Science, Section of Wood Modification and Preservation, Sari Agriculture and Natural Resources University, Sari,

Iran.Bari_Lenzites@yahoo.com,E.Bari@Sanru.ac.ir

${ }^{2}$ Wood Science \& Technology Department, Faculty of Civil Engineering, Shahid Rajaee Teacher Training University (SRTTU), Tehran, Iran. htaghiyari@yahoo.com

${ }^{3}$ Department of Wood Biology, University of Hamburg, Leuschnerstr 91, 21031 Hamburg, Germany.

${ }^{4}$ Department of Wood Science and Technology, University of Natural Resources, Azad University of Sari, Sari, Iran.

${ }^{5}$ Department of Wood Modification and Preservation, Gorgan Agriculture and Natural Resources University, Gorgan, Iran.

^Corresponding author: htaghiyari@srttu.edu

Received: 17.10.2013 Accepted: 21.05. 2014
} 


\section{MATERIALS AND METHODS}

\section{Specimen preparation}

Polypropylene, commercial grade name Z30S, was purchased from Bandar-Emam Petrochemical Company in powder form. Detailed technical specifications are in Table 1.

Table 1. Technical specifications of polypropylene used.

\begin{tabular}{cccccc}
\hline $\begin{array}{c}\text { Commercial } \\
\text { grade }\end{array}$ & $\begin{array}{c}\text { Density } \\
\left(\mathrm{g} / \mathrm{cm}^{3}\right)\end{array}$ & $\begin{array}{c}\text { Melting point } \\
\left({ }^{\circ} \mathrm{C}\right)\end{array}$ & $\begin{array}{c}\text { Glassy } \\
\text { transition } \\
\text { temperature } \\
\left({ }^{\circ} \mathrm{C}\right)\end{array}$ & $\begin{array}{c}\text { Polymer } \\
\text { structure }\end{array}$ & $\begin{array}{c}\text { Melt flow } \\
\text { index } \\
\left(230^{\circ} \mathrm{C}\right)\end{array}$ \\
\hline \hline Z30S & 0,9 & $165-171$ & $-8^{\circ} \mathrm{C}$ & $\begin{array}{c}\text { Semi- } \\
\text { crystalline } \\
\text { homo-polymer }\end{array}$ & $16 \mathrm{~g} / 10 \mathrm{~min}$ \\
\hline
\end{tabular}

Poplar (Populus nigra L) sawdust was passed through laboratory sieves. The fraction between 40 and 60 mesh screens was used. The sawdust was dried for 24 hours at $103 \pm 5^{\circ} \mathrm{C}$. To prevent moisture absorption from the air, sawdust was kept in plastic bags. As compatibilizer, $2 \%$ of maleic anhydride grafted polyethylene (MAPP; commercial grade name PP-G 101), with the melt flow index of 50-80 g/10 min and glassy transition temperature of minus $24^{\circ} \mathrm{C}$ was used.

Nanoclay was produced by Southey-Clay Company (Gonzales, Texas, USA). Specifications of the nanoclay used are shown in table 2.

Table 2. Technical specifications of the nanoclay used in the production of wood-plastic composites.

\begin{tabular}{|c|c|c|c|c|}
\hline $\begin{array}{l}\text { Commercial } \\
\text { grade }\end{array}$ & $\begin{array}{l}\text { Chemical structure of the } \\
\text { modifier }\end{array}$ & $\begin{array}{l}\text { Organic } \\
\text { modifier }\end{array}$ & $\begin{array}{c}\text { Modifier } \\
\text { concentration } \\
(\mathrm{meq} / 100 \mathrm{~g})\end{array}$ & $\begin{array}{c}\text { Weight loss } \\
\text { on ignition } \\
(\%)\end{array}$ \\
\hline Cloisite $(15 \mathrm{~A}$ & $\begin{array}{c}\mathrm{CH}_{3} \\
\mathbf{1} \\
\mathrm{CH}_{3}-\underset{\mathrm{N}}{\mathrm{N}^{+}}-\mathrm{HT} \\
\mathrm{HT}\end{array}$ & $2 \mathrm{M}_{2} \mathrm{HT}^{1}$ & 125 & 43 \\
\hline
\end{tabular}

${ }^{1} 2 \mathrm{M} 2 \mathrm{H}=$ dimethyl, dihydrogenatedtallow, quaternary ammonium.

Dried wood flour and polyethylene powder were mixed based on their weight ratios (Table 3). Once the ingredients of each composite formulation were weighed to a $0,01 \mathrm{~g}$ precision, they were manually mixed and again kept in plastic bags before the compression molding process. Care was taken to mix the ingredients as homogenously as possible. 
Table 3. WPC formulations for the five treatments in the present study

\begin{tabular}{lcccc}
\hline Treatment code & $\begin{array}{c}\text { Wood flour } \\
\text { content (\%) }\end{array}$ & $\begin{array}{c}\text { Polypropylene } \\
\text { content (\%) }\end{array}$ & MAPP $^{1}(\%)$ & $\begin{array}{c}\text { Nanoclay content } \\
(\%)\end{array}$ \\
\hline \hline WPC-Control & 40 & 58 & 2 & 0 \\
\hline WPC-2NC & 40 & 56 & 2 & 2 \\
\hline WPC-4NC & 40 & 54 & 2 & 4 \\
\hline WPC-6NC & 40 & 52 & 2 & 6 \\
\hline
\end{tabular}

${ }^{1} \mathrm{MAPP}=$ maleic anhydride grafted polyethylene

\section{WPC production}

The composite panels were produced using hot press compression molding. Panels were $30 \times 28 \mathrm{~cm}^{2}$, and $1 \mathrm{~cm}$ in thickness. Press temperature was $185^{\circ} \mathrm{C}$ and pressing time was $9 \mathrm{~min}$. After hot pressing, panels were kept in a cold press for $5 \mathrm{~min}$. Density of the WPC panels was $0,90 \mathrm{~g} / \mathrm{cm}^{3}$. Three replicate panels were produced for each composite formulation so that the total number of panels was 12. From each panel, five replicate specimens were prepared. The total number of replications for each treatment was 15 , totaling 60 specimens for all treatments. Panels were kept at room conditions for one week before specimens were cut for physical and mechanical tests.

\section{Fungal degradation test}

Nano-clay/WPC specimens with the size according to the European standard EN 113 were dried at $103^{\circ} \mathrm{C}$ for $24 \mathrm{~h}$, weighed and autoclaved at $121 \mathrm{oC}$ for $20 \mathrm{~min}$. Samples were exposed in Kolle flasks on $4.8 \%$ malt extract agar to the white-rot fungi Physisporinus vitreus (Pers.: Fr.) P. Karsten isolate 136, Pleurotus ostreatus (Jacq.: Fr.) Kummer 11 and Trametes versicolor (L.: Fr.) Pilát 325 as well as the brown-rot species Antrodia vaillantii (DC.: Fr.) Ryv. 240 and Coniophora puteana (Schum.: Fr.) P. Karsten 167 deriving from the Hamburg Wood Biology collection. Incubation was done at $25^{\circ} \mathrm{C}$ and $65 \%$ relative humidity for 16 weeks. Five replicates were prepared for each panel, totaling 15 replicate specimens for each treatment. At cultivation end, outer mycelia were removed, the specimens again dried at $103^{\circ} \mathrm{C}$ for $24 \mathrm{~h}$ and weighed to determine the fungal mass loss according to EN 113. Mass loss values were calculated as the percent of the total mass.

\section{Water absorption}

Physical property of water absorption (WA) was carried out in accordance with Iranian Standard ISIRI 9044 PB Type P2 (compatible with ASTM D1037 specifications). From each panel, five specimens were prepared, totaled 15 specimens for each treatment. Specimens were immersed in distilled water after being exposed to the fungi. WA was then measured and expressed as a percent for each specimen. The nominal size of specimens was $60 \times 30 \times 10 \mathrm{~mm}$. A digital scale was used for weighing specimens to a precision of 0,01 $\mathrm{g}$ before and after the immersion in water.

\section{Field emission scanning electron microscopy (FE-SEM)}

FE-SEM imaging was performed at thin-film laboratory, FE-SEM lab, School of Electrical \& Computer Engineering, University of Tehran. Air-dried samples were trimmed with razor blades to a final size of about $5 \times 5 \times 5 \mathrm{~mm}^{3}$, mounted onto aluminum stubs with conductive carbon paste and were sputter-coated with gold. A field-emission cathode in the electron gun provided narrower probing beams at low as well as high electron energy, resulting in both improved spatial resolution and minimized sample charging and damage. 


\section{Statistical analysis}

Statistical analysis was conducted using SAS software program, version 9,2 (2010). Two-way ANOVA was performed to discern significant difference at the $95 \%$ level of confidence. Grouping was then made between treatments using the Duncan's test. Hierarchical cluster analysis, including dendrogram and using Ward's method with squared Euclidean distance intervals, was carried out within SPSS/18 (2010). Fitted-line and scatter plots were made using Minitab software, version 16.2.2, 2010.

\section{RESULTS AND DISCUSSION}

The FE-SEM images in figure 1 showed an even and uniform scatter of nano-clay particles in the WPCmatrix which was a prerequisite for the study.

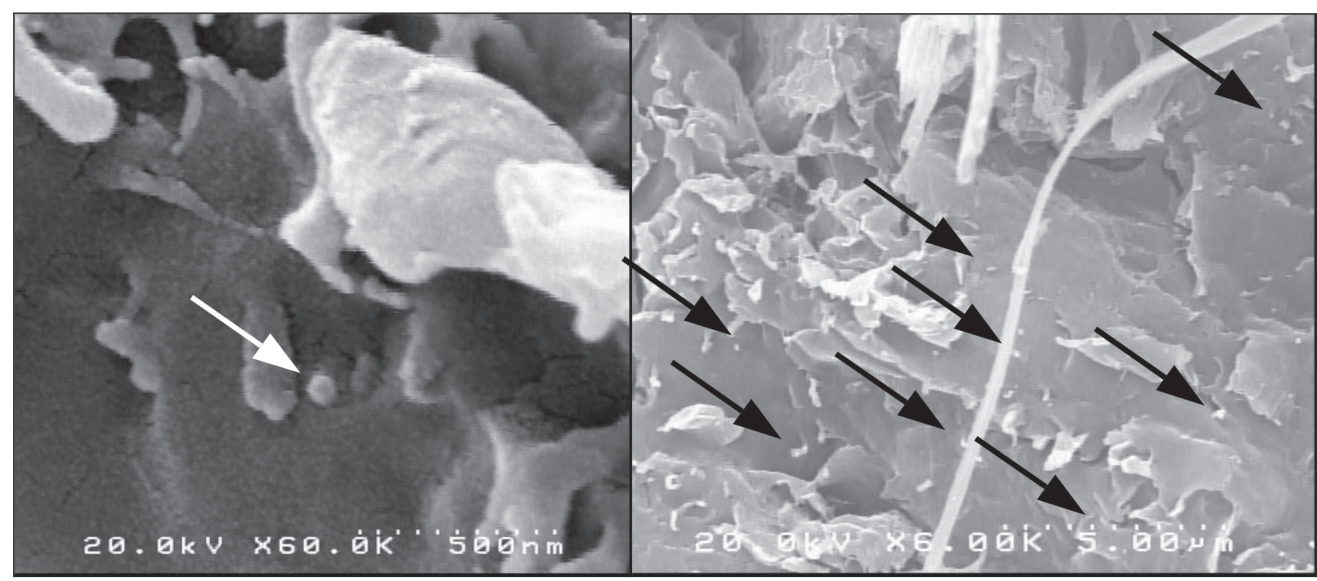

Figure 1. FE-SEM images showing clay nanoparticles $(\downarrow)$ scattered in the WPC matrix.

The mass losses (ML) of the control and nano-clay-treated samples by the five fungi are shown in figure 2. As shown by the error bars, variability in the ML values generally decreased as NC-content increased in most of the treatments as well as in all fungi species. Mean ML of the virulence beech specimens exposed to $T$. versicolor was $28,4 \%$.

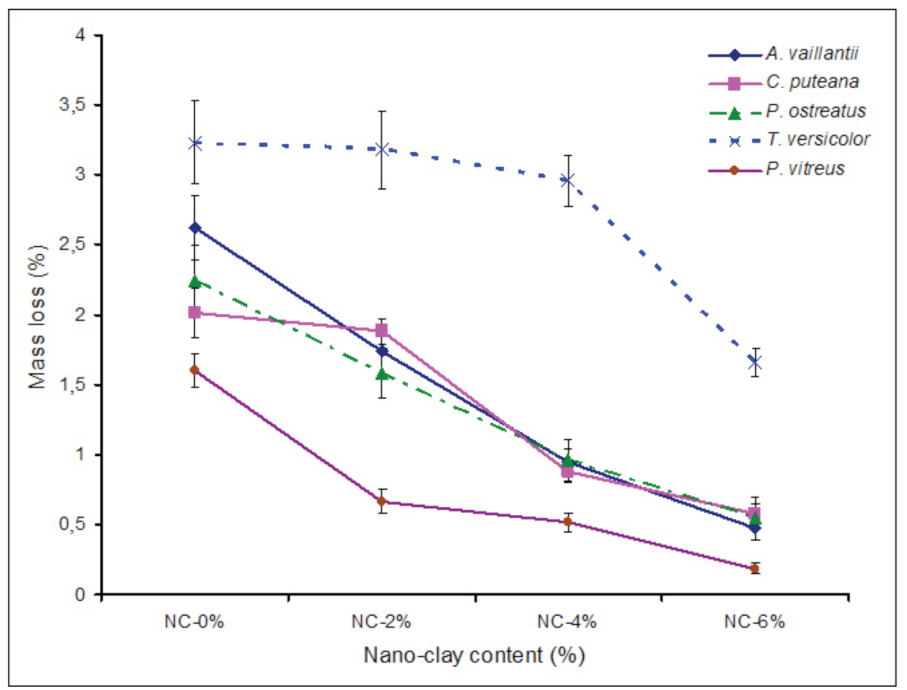

Figure 2. Mass loss (\%) produced by five fungi in WPCs with $0,2,4$, and $6 \%$ nano clay content. 
The mass losses were generally rather low, even in the untreated controls. This can be attributed to the generally low susceptibility of WPCs to fungi. The differences among the controls of the five fungi indicate an influence of the test fungus used. The most destructive fungus was T. versicolor with $3,2 \% \mathrm{ML}$ in the control and $1.6 \%$ at $6 \%$ nano-clay treatment. $P$. vitreus yielded the lowest ML among the fungi with $0,18 \%$ at $6 \%$ nano-clay.

Most white-rot fungi like $P$. ostreatus and T. versicolor prefer hardwoods, whereas brown-rotters like $A$. vaillantii and $C$. puteana grow better on softwoods (Schmidt 2006). However, there was no obvious influence of the wood species poplar used for the WPCs on the fungal group, as T. versicolor and A. vaillantii decayed the controls the most and C. puteana and P. vitreus little.

ML decreased with increasing nanoclay-content. With regard to significant protection, $T$. versicolor, was considerably inhibited at $6 \%$ NC-content. As to the less destructive $P$. vitreus, however, all three NC-contents were effective. The other three fungi showed a steady slope, proving that there should not necessarily be a threshold NC-content level.

Moreover, combined scatter-plot between the control panels versus panels with different NC-contents (2, 4, and 6\%) showed a distinct difference between the three NC-treatments. With increasing NC-content from 2 to $6 \%$ water absorption tended to significantly decrease (Figures 3 and 4); Duncan's multiple range test showed that NC-6\%-content specimens exposed to all five fungi were significantly grouped differently at $5 \%$ level of confidence. Moreover, the slopes and intercepts of the three scatter-plots were significantly different.

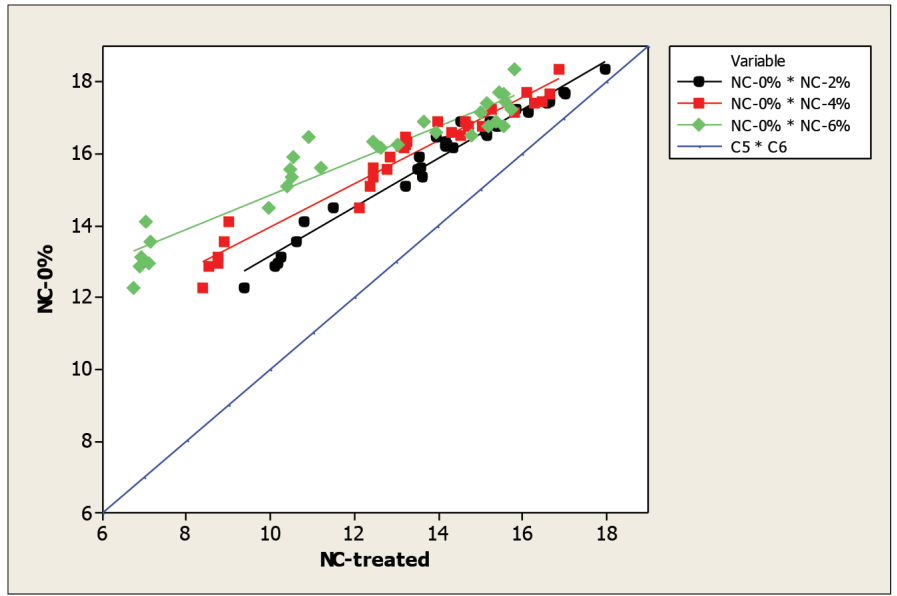

Figure 3. Combined scatter-plot of water absorption values between the control (NC-0\%) as well as nanoclay-treated (NC-treated) specimens.

This showed that the water-repellant property of nanoclay had a significant decreasing effect on water absorption in WPC, at 5\% level of confidence. Similarly, the water-repellant property of silicon-compounds decreased the water absorption in solid woods (Haghighi et al. 2013). In fact, nanoclay formed as a coupling agent in the PVC-wood flour matrix, resulting in a decrease in fluid flow. Furthermore, the bonds formed between the hydroxyl groups of the wood flour and the nanoclay particles made less hydroxyl groups available to be involved in the absorption of water molecules. Two types of bonds are formed between the nanomaterial compounds and lignin network (Rangavar 2005, Taghiyari et al. 2013). From one side, the Al in $\mathrm{Al}(\mathrm{OH})_{3}$ reacts with methoxy groups of the lignin benzene ring; and from the other side, the hydroxyl groups in $\mathrm{Al}(\mathrm{OH})_{3}$ makes a complex bond with the lignin. The formation of the bonds continues, significantly fortifying the composite-matrix. 
The fitted-line plot between the average values of ML versus water absorption based on the four different treatments (exposed to the five fungi) showed a significant correlation (R-square higher than 70\%) (Figure 4); the high and significant $\mathrm{R}^{2}$ showed a meaningful coordination between the decrease in water absorption versus the decrease in ML as NC-content increased. This implied that water absorption in WPC may be a criterion for estimating its ML. In fact, encapsulation of wood flour and clay nanoparticles by the polypropylene resin would be in a way that water as well as fungal mycelium can penetrate in a similar way, although they greatly differ in size.

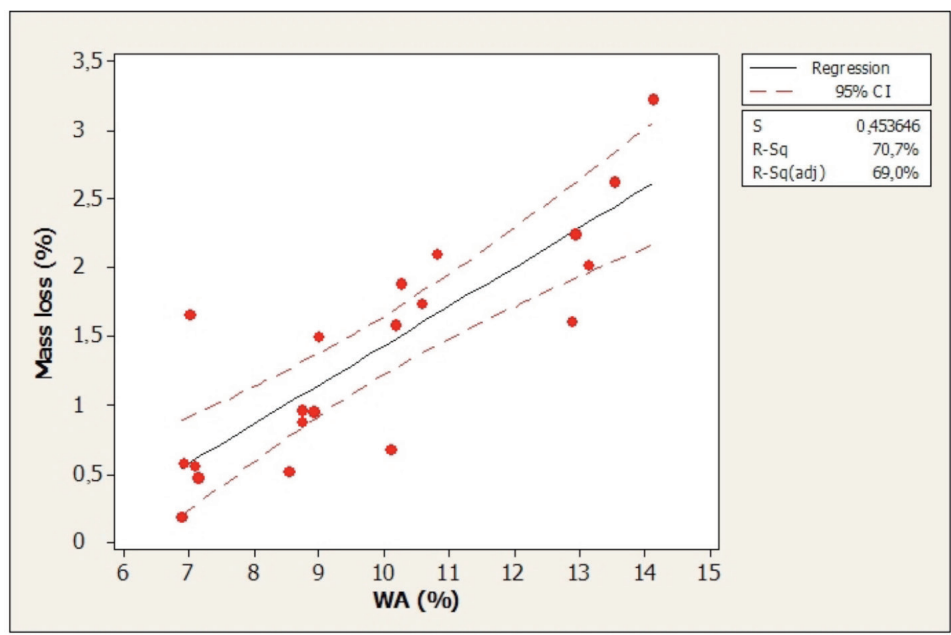

Figure 4. Fitted-line plot between the average values of water absorption and mass losses in the four WPC treatments exposed to the five fungi. WA = water absorption. 


\section{CONCLUSIONS}

Effects of nano-clay on biological durability of wood-plastic composites (WPC), made from polypropylene and poplar sawdust, against five important wood-deteriorating fungi were studied. Nano-clay significantly decreased ML of WPCs by all five fungi tested; however, the effective threshold was different for each fungus. Trametes versicolor and Physisporinus vitreus had the highest and lowest deteriorating effects, respectively. High correlation was found between the amount of water absorption and mass loss, implying that the penetration of fungus mycelium into the WPC-matrix followed a similar pattern as the penetration of water molecules.

\section{REFERENCES}

DePolo, J.L.; Baird, D.G. 2009. Particulate reinforced PC/PBT composites. II. Effect of nano-clay particles on dimensional stability and structure-property relationships. Polymer Composites 30(2): 200-213.

Fabiyi, J.S.; McDonald, A.G.; Morrell, J.J.; Freitag, C. 2011. Effects of wood species on durability and chemical changes of fungal decayed wood plastic composites. Composites: Part A 42: 501-510.

Gacitua, W.E. 2008. Influence of wood species on properties of wood/HDPE composites. PhD dissertation submitted to WMEL, Washington State University, Pullman, USA.

Haghighi Poshtiri, A.; Taghiyari, H.R.; Karimi, A.N. 2013. The optimum level of nano-wollastonite consumption as fire-retardant in poplar wood (Populus nigra). International Journal of Nano Dimension 4(2): 141-151.

Kim, J.; Harper, D.P.; Taylor, A.M. 2008. Effect of wood species on water sorption and durability of wood-plastic composites. Wood Fiber Science 40(4): 519-531.

Laks, P.E.; Richter, D.L.; Larkin, G.L. 2000. Biological deterioration of wood-base composite panels. Wood Design Focus 11(4): 7-14.

Mankowski, M.; Morrell, J.J. 2000. Patterns of fungal attach in wood-plastic composites following exposure in a soil block test. Wood and Fiber Science 32(3): 340- 345.

Moghimi, A. 2012. Solid Phase Extraction of amount $\mathrm{Cu}$ (II) using C18 disks modified Schiff baseChitosan grafted multiwalled carbon nanotubes. International Journal of Bio-Inorganic Hybrid Nanomaterials 1(2): 105-114.

Morrell, J.J.; Stark, N.M.; Pendleton, D.E.; McDonald, A.G. 2006. Durability of Wood-Plastic Composites. Wood Design Focus 16(3): 7- 10.

Palanti, S.; Feci, E.; Predieri, G.; Francesca, V. 2012. Copper complexes grafted to amino-functionalized silica gel as wood preservatives against fungal decay: Mini-blocks and standard test. BioResources 7(4): 5611-5621.

Pati, R. 2012. Molecule for electronics: A myriad of opportunities comes with daunting challenges. Journal of Nanomaterials \& Molecular Nanotechnology 1:1 doi: 10.4172/2324-8777.1000e104.

Pendleton, D.E.; Hoffard, T.A.; Adcock, T.; Woodward, B.; Wolcott, M.P. 2002. Durability of an extruded HDPE/wood composite. Forest Products Journal 52(6): 21- 27. 
Rangavar, H. 2005. Instructions for wood-cement composite-boards using hardwoods. Wood Technology and Equipment Journal 236- 241.

Saber, R.; Shakoori, Z.; Sarkar, S.; Tavoosidana, Gh.; Kharrazi, Sh.; Gill, P. 2013. Spectroscopic and microscopic analyses of rod-shaped gold nanoparticles interacting with single-stranded DNA oligonucleotides. IET Nanobiotechnology 7(2): 42- 49.

Schmidt, 0. 2006. Wood and tree fungi. Biology, damage, protection, and use. Springer, Berlin, Heidelberg, New York: $334 \mathrm{p}$.

Stark, N.M. 1997. Effect of species and particle size on properties of wood-flour-filled polypropylene composites. In: Proceeding of functional fillers for thermoplastic and thermosets. December $8-10$, San Diego, California, USA.

Taghiyari, H.R.; Farajpour Bibalan, O. 2013. Effect of copper nanoparticles on permeability, physical, and mechanical properties of particleboard. European Journal of Wood and Wood Products 71(1): 69- 77.

Taghiyari, H.R.; Mobini, K.; Sarvari Samadi, Y.; Doosti, Z.; Karimi, F.; Asghari, M.; Jahangiri, A.; Nouri, P. 2013. Effects of nano-wollastonite on thermal conductivity coefficient of medium-density fiberboard. Journal of Nanomaterials and Molecular Nanotechnology 2:1 doi. 10.4172/2324-8777.1000106. 